\title{
Microbiota cloacal aeróbia de cracídeos cativos no Rio Grande do Sul e sua susceptibilidade a antimicrobianos ${ }^{1}$
}

\author{
Helton Fernandes Santos ${ }^{2}$, Maristela Lovato Flôres ${ }^{3}$, Valéria Maria Lara ${ }^{4}$, \\ Mariana Sá e Silva ${ }^{3}$, Luciano Battisti ${ }^{2}$ e Luciane T. Lovato ${ }^{4 *}$
}

\begin{abstract}
Santos H.F., Flôres M.L., Lara V.M., Sá M.F., Battisti L. \& Lovato L.T. 2010. [Cloacal microbiota identification and evaluation of the antimicrobial resistance in captive cracids from Rio Grande do Sul, Brazil.] Microbiota cloacal de cracídeos cativos no Rio Grande do Sul e sua susceptibilidade a antimicrobianos. Pesquisa Veterinária Brasileira 30(12)1077-1082. Centro de Ciências Rurais, Universidade Federal de Santa Maria, Camobi, Santa Maria, RS 97105-900, Brazil. E-mail: llovato@ smail.ufsm.br

Cracids are wildlife Galliformes which inhabits the America's tropical forests. Fifty one cloacal swabs were collected from 10 different species of captive cracids from the Rio Grande do Sul State during 2007. The cloacal swab samples were submitted to bacterial isolation, identification and, subsequently; antimicrobial susceptibility testing. Ninety three bacterial isolates were obtained from the cracid population examined. The most prevalent among the isolates were Escherichia coli, and bacteria from the Staphylococcus and Streptococcus genera. All samples tested in this study were negative for Salmonella spp. The antimicrobial susceptibility tests showed that none of the 93 strains presented resistance to the antimicrobial imipinem. In addition, the lower percentages of resistance were observed against cloranfenicol and ciprofloxacine. The bacteria genus and species with the highest percentage of resistance to the different antimicrobials examined were E. coli, Serratia marcescens, Staphylococcus spp. and Streptococcus spp. In conclusion, the data presented in this article demonstrate that the cloacal microbiota of the reported cracid population is composed of several bacterial genera and species and multi-drug resistance may be a problem for the future, since some strains showed elevated percentage of resistance against several different antimicrobials.
\end{abstract}

INDEX TERMS: Antimicrobial resistance, Cracidae, epidemiology, wildlife, cloacal microbiota.

RESUMO.- Os cracídeos são aves silvestres que habitam as matas tropicais da América. Foram coletadas, no ano de 2007, amostras cloacais de 51 aves de dez espécies diferentes de cracídeos mantidos em cativeiros no Estado do Rio Grande do Sul. A partir dos swabs, colhidos assepticamente, foi realizado o isolamento e a caracterização bacte-

\footnotetext{
${ }^{1}$ Recebido em 18 de dezembro de 2009.

Aceito para publicação em 19 de outubro de 2010.

2 Programa de Pós-Graduação em Medicina Veterinária, área de concentração em Medicina Veterinária Preventiva, Centro de Ciências Rurais (CCR), Universidade Federal de Santa Maria (UFSM), Camobi, Santa Maria, RS 97105-900, Brasil.

${ }^{3}$ Departamento de Medicina Veterinária Preventiva, CCR-UFSM, Santa Maria, RS.

${ }^{4}$ Departamento de Microbiologia e Parasitologia, Centro de Ciências da Saúde, UFSM, Santa Maria, RS. *Autor para correspondência: llovato@smail.ufsm.br
}

riana e o teste de susceptibilidade antimicrobiana dos isolados. Foram identificadas 93 cepas de bactérias. As bactérias mais frequentemente isoladas foram Escherichia coli, Staphylococcus spp. e Streptococcus spp. Todas as amostras foram negativas para o isolamento de Salmonella spp. O resultado do teste de sensibilidade mostrou que dentre as 93 cepas isoladas, todas foram sensíveis apenas ao imipinem. Adicionalmente, os menores percentuais de resistência foram observados frente ao cloranfenicol e ciprofloxacina. Os gêneros e espécies bacterianas com maior percentual de resistência a diferentes antibióticos testados foram Escherichia coli, Serratia marcescens, Staphylococcus aureus e Streptococcus spp. Com os resultados obtidos no presente trabalho, concluí-se, que a população de cracídeos estudada apresenta sua microbiota cloacal composta por vários gêneros e espécies bacterianas e que a multirresistencia pode ser um problema no futuro, uma vez 
que algumas cepas isoladas mostraram percentuais elevados de resistência a diferente antimicrobianos.

TERMOS DE INDEXAÇÃO: Resistência antimicrobiana, Cracidae, epidemiologia, animais silvestres, microbiota cloacal.

\section{INTRODUÇÃO}

A família Cracidae (mutuns, jacus, jacutingas e araquãs) um grande grupo de aves frugívoras, é de ampla distribuição geográfica sendo encontradas desde o México até a Argentina. No Brasil já foram identificadas 25 espécies diferentes (Evêncio 2006), entretanto, algumas dessas aves correm risco de extinção. Aproximadamente metade dos grandes jacus e mutuns é considerada vulnerável ou é ameaçado. Essas espécies têm um papel ecológico muito importante, principalmente na regeneração de florestas (Sedaghatkish 1996). A oportunidade de contato entre estas aves silvestres e aves domésticas está aumentando devido à destruição do seu habitat natural, trazendo estes animais para as proximidades das áreas de criação em busca de alimento, contribuindo para a transmissão de possíveis patógenos.

O estudo da microbiota bacteriana de aves silvestres clinicamente saudáveis é um passo importante para a compreensão da epidemiologia das doenças bacterianas que podem afetar as suas populações e espécies semeIhantes (Dobbin et al. 2005). A microbiota fecal de aves silvestres tem sido pouco estudada, há poucos trabalhos sobre a ocorrência de bactérias de importância em saúde pública, particularmente no Brasil. As bactérias isoladas com maior frequência em material fecal de passeriformes são Escherichia coli, Staphylococcus spp. e Streptococcus spp. (Brittingham et al. 1988, D'Aloia et al. 1996). Patógenos com potencial zoonótico como Campylobacter spp, Salmonella spp. e Listeria spp. também foram isolados dessas aves (Steele et al. 2005, Epstein et al. 2007, Ganapathy et al. 2007). Além disso, já foi relatada a possibilidade de transmissão de patógenos, como Salmonella spp. e Escherichia coli O157:H7 de animais de zoológicos e circos para seres humanos, principalmente crianças, sendo que a transmissão desses agentes ocorreu provavelmente pelo simples ato de acariciar os animais e/ou pelo toque das mãos nas grades de proteção e nos moirões de madeiras de segurança. (Bender \& Shulman 2004).

A pressão seletiva exercida pelo uso inadequado de antimicrobianos culminou no surgimento de cepas bacterianas multirresistentes, configurando um problema de saúde pública e fazendo com que estudos de susceptibilidade sejam de grande importância. Vários estudos com cepas de bactérias isoladas de aves silvestres têm demonstrado altos índices de resistência a antimicrobianos, mesmo em amostras de animais que provavelmente nunca foram tratados com antibióticos (Livermore et al. 2001, Middleton \& Ambrose 2005, DeBoer et al. 2007, Dolejska et al. 2007, Gibbs et al. 2007). No Brasil, estudo realizado em Minas Gerais, reportou elevado índice de resistência bacteriana em amostras oriundas de pássaros selvagens de vida livre (Nascimento et al. 2003). O contato com pessoas, animais domésticos e mesmo com antibióticos naturais produzidos por microrganismos ambientais pode ter conferido resistência a antibióticos em muitas bactérias isoladas de animais silvestres que nunca receberam antimicrobianos (Gibbs et al. 2007).

Devido ao pouco conhecimento da microbiota cloacal de aves silvestres e do perfil de sensibilidade das bactérias isoladas e, ainda, pela possibilidade destas aves abrigarem patógenos para humanos e outros animais, o presente estudo objetivou identificar a microbiota cloacal aeróbia em cracídeos mantidos em cativeiro no Estado do Rio Grande do Sul, Brasil, e pesquisar o perfil de resistência das amostras identificadas frente a doze antimicrobianos de importância em saúde pública.

\section{MATERIAL E MÉTODOS}

Em 2007 foram obtidas amostras de 51 aves de dez espécies diferentes de cracídeos (Quadro 1), mantidas em cinco criatórios e três zoológicos do Rio Grande do Sul, Brasil. As aves estavam saudáveis e confinadas em recintos telados. A dieta consistia de duas refeições diárias de frutas, legumes, sementes e ração peletizada de galinhas. Nos zoológicos encontravamse separadas por espécie, sem contato com outros animais. Em dois criatórios conservacionistas estavam em contato com outras espécies de aves silvestres (tucanos, papagaios, pássaros em geral); todos saudáveis. As coletas foram realizadas de acordo com as diretrizes impostas e mediante a autorização oficial do Instituto Brasileiro do Meio Ambiente e dos Recursos Naturais, IBAMA (SISBIO n.11629-1). A colheita foi realizada utilizando-se dois swabs estéreis por ave, sendo que um foi acondicionado em solução salina tamponada (PBS) esterilizada e o outro em caldo tetrationato (TB). Posteriormente, foram armazenados à temperatura de $4^{\circ} \mathrm{C}$ até o seu processamento, realizado em um período inferior a 24 horas. As amostras acondicionadas em PBS foram semeadas diretamente em ágar MacConkey (MCA) e em ágar sangue de carneiro (5\%) (AS), incubadas sob aerobiose a $37^{\circ} \mathrm{C}$, com leituras em 24 e 72 horas. Para o isolamento de Salmonella spp., as amostras transportadas em TB foram incubadas a $37^{\circ} \mathrm{C}$ durante 24 horas; após essa pré-incubação, os isolados foram semeadas em ágar Hektoen $(\mathrm{AH})$ e incubadas em aerobiose a $37^{\circ} \mathrm{C}$ com leituras em 24 e 48 horas. As colônias bacterianas isoladas foram submetidas à identificação por características bioquímico-fisiológicas convencionais e com kit comercial para identificação de enterobactérias (Probac ${ }^{\odot}$, São Paulo) (Quinn et al. 1994, Konemam et al. 2001).

Todas as bactérias identificadas foram submetidas ao teste de susceptibilidade aos seguintes antibióticos: amicacina $(30 \mu \mathrm{g})$, amoxicilina $(10 \mu \mathrm{g})$, ampicilina $(10 \mu \mathrm{g})$, cefalexina $(30 \mu \mathrm{g})$, ciprofloxacina $(0,5 \mu \mathrm{g})$, ciprofloxacina $(0,5 \mu \mathrm{g})$, gentamicina $(10 \mu \mathrm{g})$, neomicina $(30 \mu \mathrm{g})$, oxacilina $(1 \mu \mathrm{g})$, penicilina $\mathrm{G}(10 \mathrm{U})$, imipenem $(10 \mu \mathrm{g})$ e tobramicina $(10 \mu \mathrm{g})$, conforme a técnica proposta por Bauer et al. (1966) com modificações propostas pelo National Committee for Clinical Laboratory Standards (NCCLS/CLSI, 2002). No controle de qualidade foram utilizadas as cepas: Escherichia coli ATCC 25922, Klebsiella oxytoca (CCT 0182), Serratia marcescens (ATCC 14756), Staphylococcus aureus (ATCC 25923), e Staphylococcus sp. (ATCC 12715). 


\section{RESULTADOS E DISCUSSÃO}

Nos cracídeos estudados foram identificadas 93 cepas de bactérias (Quadro 1). Em três amostras cloacais não foi identificado nenhum tipo de bactéria com a metodologia empregada. A ausência de crescimento de bactérias nesse tipo de amostra também foi reportado por Brittingham et al. (1988) e Nascimento et al. (2003) que relatam que resultados negativos podem ocorrer devido à redução da população bacteriana durante o transporte/estocagem das amostras, mesmo em meios e em temperatura adequadas.

Escherichia coli foi isolada em $70,5 \%$ das amostras. Esse resultado era esperado, uma vez que já foi demonstrado que essa espécie bacteriana é frequentemente isolada da microbiota do trato digestório de aves domésticas e silvestres em condições normais (Barnes \& Valliancourt 2003, Almeida et al. 2005, Mattes et al. 2005). Estudos realizados por D'Aloia et al. (1996) e Steele et al. (2005) também demonstraram frequencias elevadas, respectivamente, $71 \%$ e $90 \%$, em amostras fecais de gaivotas e de espécies de aves marinhas. Entretanto, em amostras cloacais obtidas de passeriformes, foram observados índices de isolamento de Escherichia coli de 1,0-9,5\% (Brittingham et al. 1988, Gibbs et al. 2007). O uso de metodologias diferentes de isolamento bacteriano pode explicar a discrepância entre os resultados obtidos no presente trabalho e os trabalhos supracitados. Além disso, fatores nutricionais e de manejo podem alterar a microbiota fecal de aves (Godoy-Vitorino et al. 2008), ocasionando variados percentuais de isolamento bacteriano em amostras cloacais entre espécies estudadas.

Bactérias do gênero Staphylococcus spp. foram isoladas em $49 \%$ das amostras cloacais de cracídeos. Esse gênero é comumente isolado da microbiota fecal de aves segundo Andreasen (2003), com diferentes percentuais de isolamento (Brittingham et al. 1988, Aarestrup et al. 2000). Neste estudo, Staphylococcus aureus foi isolado em $29,4 \%$ das amostras fecais estudadas. A identificação dessa espécie é importante, pois $S$. aureus é importante agente etiológico de infecções articulares em aves (Koneman 2001).

O terceiro grupo de bactérias com maior número de isolados foi o gênero Streptococcus, com percentual de isolamento de $25,4 \%$. Apesar de a importância dos estreptococos já estar bem estabelecida em diversas espécies de animais domésticos, poucos são os dados na literatura que descrevem e apontam a importância desse gênero em espécies de aves silvestres. Brittingham et al. (1988) identificaram estreptococos em $18 \%$ das amostras fecais de

Quadro 1. Agentes bacterianos isolados em amostras de swabs cloacais de espécies de cracídeos cativos, no Estado do Rio Grande do Sul, durante o ano de 2007

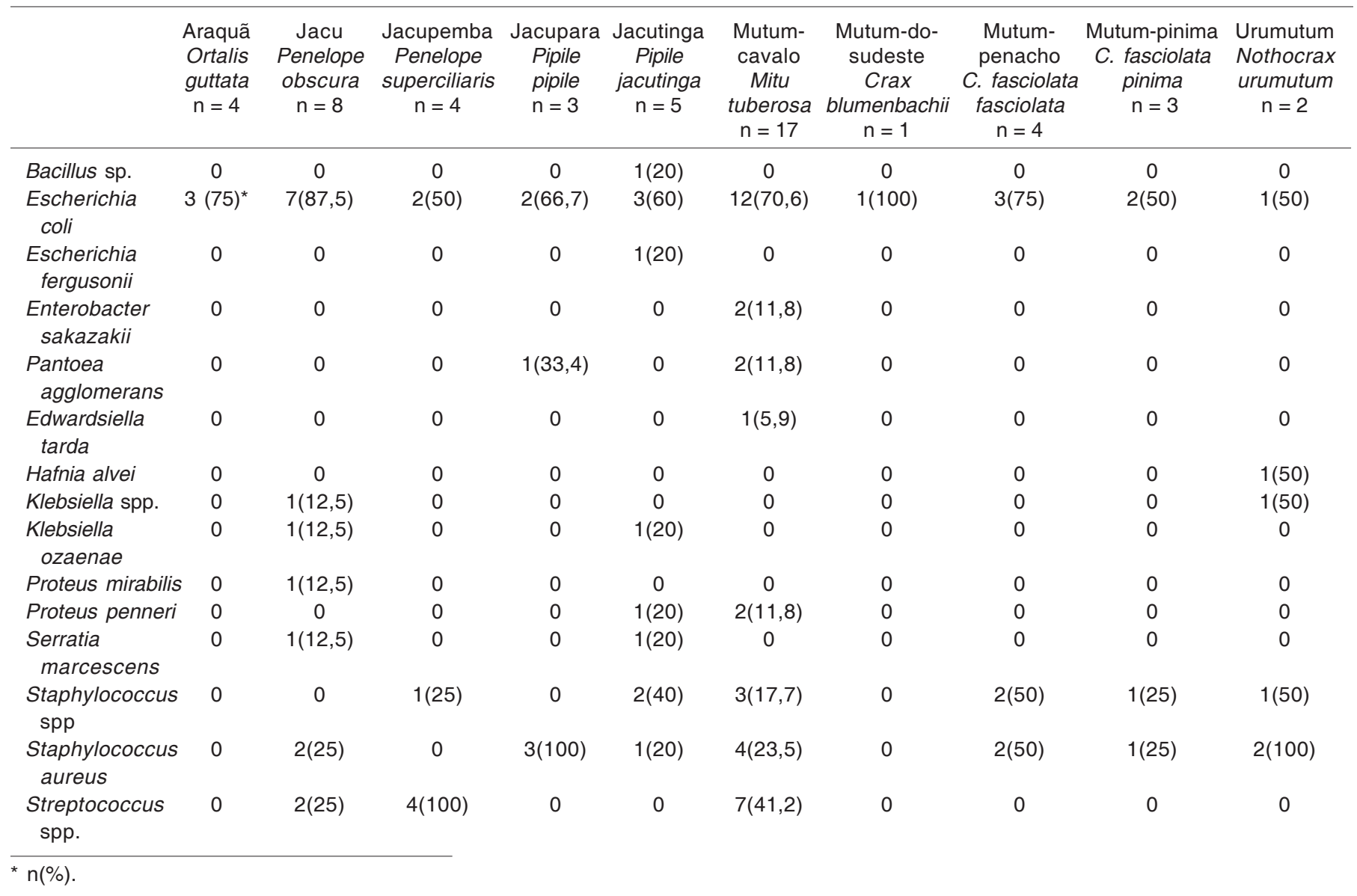


Quadro 2. Resultados do percentual de resistência de bactérias isoladas de amostras cloacais de espécies de cracídeos cativos, no Estado do Rio Grande do Sul, durante o ano de 2007

\begin{tabular}{|c|c|c|c|c|c|c|c|c|c|c|}
\hline & E. coli & $\begin{array}{l}\text { E. agglo- } \\
\text { merans }\end{array}$ & $\begin{array}{l}P . \text { mira- } \\
\text { bilis }\end{array}$ & $\begin{array}{l}\text { Klebsie-. } \\
\text { Ila spp }\end{array}$ & $\begin{array}{c}\text { K. ozae- } \\
\text { nae }\end{array}$ & $\begin{array}{l}\text { S. marces- } \\
\text { cens }\end{array}$ & $\begin{array}{l}\text { S. au- } \\
\text { reus }\end{array}$ & $\begin{array}{l}\text { Staphyloco- } \\
\text { ccus spp. }\end{array}$ & $\begin{array}{l}\text { Streptoco- } \\
\text { ccus spp. }\end{array}$ & Resistência \\
\hline Amicacina & 27,8 & 0 & 0 & 0 & 0 & 50 & 66,7 & 50 & 53,8 & 35,5 \\
\hline Amoxicilina & 21,9 & 0 & 100 & 100 & 50 & 50 & 0 & 0 & 0 & 15,8 \\
\hline Ampicilina & 18,7 & 0 & 100 & 100 & 50 & 50 & $N D^{*}$ & 0 & 16,7 & 20,3 \\
\hline Cefalotina & 36,1 & 0 & 100 & 0 & 50 & 100 & 18,2 & 0 & 66,7 & 30 \\
\hline Ciprofloxacina & 2,8 & 0 & 0 & 0 & 0 & 50 & 6,7 & 0 & 7,7 & 4,3 \\
\hline Cloranfenicol & 0 & 0 & 0 & 0 & 0 & 0 & ND & 0 & 7,7 & 2,1 \\
\hline Gentamicina & 15,2 & 0 & ND & 0 & 0 & 50 & 46,7 & 33,3 & 70 & 27 \\
\hline Imipinema & 0 & 0 & 0 & 0 & 0 & 0 & 0 & 0 & 0 & 0 \\
\hline Neomicina & 55,5 & 33,4 & 0 & 0 & 0 & 100 & 28,6 & 10 & 46,1 & 36,9 \\
\hline Oxacilina & ND & ND & ND & ND & ND & ND & 57,1 & 71,4 & ND & 67,1 \\
\hline Penicilina & 96,7 & 100 & 100 & 100 & 100 & 100 & 66,7 & 55,5 & 61,5 & 79,3 \\
\hline Tobramicina & ND & ND & ND & ND & ND & ND & 83,4 & 40 & 72,7 & 58,1 \\
\hline
\end{tabular}

${ }^{*} \mathrm{ND}=$ não testada.

aves silvestres, e comentaram que podem existir diferenças significativas entre espécies de passeriformes e picapaus, inclusive em relação ao tipo de alimentação, com maior porcentagem de isolamento nas aves onívoras quando comparadas a aves que ingerem restos de carcaças.

Embora E. coli e as bactérias do gênero Staphylococcus possam causar intoxicação alimentar, as bactérias do gênero Salmonella são as mais freqüentemente isoladas de surtos (Chomel et al. 2007). Aves silvestres podem servir de reservatórios dessa bactéria, como foi observado na Noruega em um surto de salmonelose em humanos associado às aves aquáticas (Refsum et al. 2002). No presente estudo, não foi obtido nenhum isolado de SalmoneIla spp.. A prevalência de salmonelas em aves silvestres sadias é baixa, o que pode conferir resultados negativos, como observado no presente estudo e em outros (Kapperud \& Rosef 1983, Brittingham et al. 1988, Ganapathy et al. 2007). Também o método de colheita pode interferir nos resultados, uma vez que swabs cloacais de aves podem não ser efetivos para detectar as bactérias quando estas estão em número reduzido (Bichler et al.1996), o que pode explicar os resultados negativos obtidos neste estudo.

Além dos já citados, outros isolados foram identificados como Bacillus sp., Escherichia fergusonii, Enterobacter sakazakii, Pantoea agglomerans (Enterobacter agglomerans), Edwardsiella tarda, Hafnia alvei, Klebsiella spp., Klebsiella ozaenae, Proteus mirabilis, Proteus penneri e Serratia marcescens. Essas espécies têm sido identificadas em outros estudos como integrantes comuns da microbiota do trato digestório e podem se constituir como agentes oportunistas de infecções (D'Aloia et al. 1996, Gibbs et al. 2007).

Os resultados referentes ao teste de susceptibilidade a antimicrobianos estão apresentados no Quadro 2. As espécies Hafnia alvei, Edwardsiella tarda, Enterobacter sakazakii, Escherichia fergusonii, Pantoea agglomerans e Proteus penneri demonstraram sensibilidade a todos os antimicrobianos testados. Todas as bactérias isoladas foram sensíveis ao imipinema. Os menores percentuais de resistência foram observados frente ao cloranfenicol e a ciprofloxacina.
Com relação a esse último antimicrobiano, estudos anteriores já observaram que bactérias da microbiota fecal de aves silvestres apresentavam um índice menor de resistência a ciprofloxacina (Livermore et al. 2001, Middleton \& Ambrose 2005).

Avaliando somente o percentual de resistência, observou-se que cepas de Staphylococcus spp. e S. aureus que perfizeram $71,4 \%$ e $57,1 \%$ dos isolados resistentes, respectivamente. É importante enfatizar que Escherichia coli, Serratia marcescens, Staphylococcus aureus e Streptococcus spp. foram os gêneros e espécies bacterianas com maior percentual de resistência a diferentes antimicrobianos, podendo configurar o possível surgimento, no futuro, de cepas multirresistentes. Estudos realizados com intuito de avaliar a resistência de cepas de Escherichia coli oriundas de aves silvestres (Livermore et al. 2001, Sayah et al. 2005, Dolejska et al. 2007, Gibbs et al. 2007), demonstraram o ocorrência de cepas multirresistentes. Este dado reveste-se de relevância tendo em vista que, no momento das colheitas, foi observado que outras espécies de pássaros tinham acesso a fezes desses cracídeos possibilitando a veiculação desta bactéria para outros animais, locais, e inclusive, para humanos.

A resistência bacteriana atualmente é um problema de saúde pública. A utilização excessiva e inadequada de antibióticos tem propiciado o surgimento de cepas multirresistentes. Contudo, já foi comprovado que muitas bactérias podem tornar-se resistentes a determinado antimicrobiano através de transferência genética ou mesmo pela pressão exercida por antibióticos naturais produzidos por diversos microrganismos presentes no meio ambiente mesmo sem nunca terem sido expostas (Koshland 1994, Gibbs et al. 2007). No Brasil, Nascimento et al. (2003) demonstraram altas taxas de resistência a antimicrobianos, em bactérias de origem fecal de pássaros selvagens da mata atlântica, que possivelmente nunca foram tratados com antibióticos. O desenvolvimento de resistência bacteriana assim como a identificada no presente trabalho, pode ser explicado por algumas teorias com: 1) através do contato com fezes de animais domésticos, uma vez que se tratando de aves elas podem ter migrado de uma área a 
outra; 2) através de contato direto com humanos, uma vez que são aves de cativeiro, o que possibilita a troca genética entre as bactérias de origens diferentes; e 3) através de ração comercial para aves de produção, o que consiste a alimentação básica no cativeiro, na qual é comum a utilização de antimicrobianos como promotores de crescimento. No entanto, ao observar as altas taxas de resistência dos cocos Gram + à oxacilina, esse fato torna-se preocupante uma vez que este antibiótico não é utilizado em rações comerciais. Assim tal resistência pode ter ocorrido por pressão natural ou por troca genética entre as bactérias.

Em resumo, apesar do presente estudo não ter isolado bactérias de importância em saúde pública e tampouco ter evidenciado e caracterizado a ocorrência de cepas multirresistentes na população de cracídeos estudados no Rio Grande do Sul, mesmo assim merece atenção, uma vez que alguns isolados apresentaram elevado percentual de resistência frente a alguns antimicrobianos, podendo no futuro evoluir para multirresistentes, um problema atual e relevante de saúde pública.

Agradecimentos.- À Fundação de Amparo à Pesquisa do Estado do Rio Grande do Sul (FAPERGS, no.0410512), à Embrapa-CNPSA, ao Departamento de Microbiologia e Parasitologia do DEMIP/CCS/UFSM, ao Setor de Virologia do Departamento de Medicina Veterinária Preventiva do DEMVP/CCR/UFSM, aos zoológicos e criatórios consultados, e também à CAPES pela concessão da bolsa de estudo.

\section{REFERÊNCIAS}

Aarestrup F.M., Agersl Y., Ahrens P., Jürgensen J.C., Madsen M. \& Jensen L.B. 2000. Antimicrobial susceptibility and presence of resistance genes in Staphylococci from poultry. Vet. Microbiol. 74:353364.

Almeida R.M.A., Bianchi M.D., Gonçalves Neto M.C., Souza R.R. \& Campos W.R. 2005. Microbiota da orofaringe e fezes de avestruzes (Struthio camellus) clinicamente sadios: estudos preliminares. Bolm Med. Vet. 1:49-56.

Andreasen C.B. 2003. Staphylococcosis, p.798-804. In: Calnek B.W., Barnes H.J., Beard C.W., McDougald L.R. \& Saif Y.M. (Eds), Diseases of Poultry. Blackwell Publishing Company, lowa State Press, Ames.

Barnes H.J. \& Valliancourt J.P. 2003. Colibacillosis, p.775-791. In: Calnek B.W., Barnes H.J., Beard C.W., McDougald L.R. \& Saif Y.M. (Eds), Diseases of Poultry. Blackwell Publishing Company, lowa State Press, Ames.

Bender J.B. \& Shulman S.A. 2004. Reports of zoonotic disease outbreaks associated with animal exhibits and availability of recommendations for preventing zoonotic disease transmission from animals to people in such settings. J. Am. Vet. Med. Assoc. 224: 1105-1109.

Bichler L.A., Nagaraja K.V. \& Halyorson D.A. 1996. Salmonella enteritidis in eggs, cloacal swab specimens, and internal organs of experimentally infected White Leghorn chickens. Am. J. Vet. Res. 4:489495.

Brittingham M.C., Temple S.A. \& Duncan R.M. 1988. A survey of the prevalence of selected bacteria in wild birds. J. Wildl. Dis. 24:299-307.

Chomel B.B., Belotto A. \& Meslin F.X. 2007. Wildlife, exotic pets, and emerging zoonoses. Emerg. Infect. Dis. 13:6-11.

D’Aloia M.A., Bailey T.A., Samour J.H., Naldo J. \& Howlett C. 1996. Bacterial flora of captive houbara (Chlamydotis undulata), kori (Ardeotis kori) and rufous-crested (Eupodotis ruficrista) bustards. Avian Pathol. 25:459-468.
DeBoer L.R., Slaughter D.M., Applegate R.D., Sobieski R.J. \& Crupper S.S. 2005 Antimicrobial susceptibility of staphylococci isolated from the faeces of wild turkey (Meleagris gallopavo). Appl. Microbiol. 33:382-386.

Dobbin G., Haribaron H., Daoust P., Haribaron S., Heaney S., Coles M., Price L. \& Muckle C.A. 2005. Bacterial flora of free-living Double-crested cormorant (Phalacrocorax auritus) chicks on Prince Edward Island, Canada, with reference to enteric bacteria and antibiotic resistance. Comp. Immunol. Microbiol. Infect. Dis. 28:7182.

Dolejska M., Cizek A. \& Literak I. 2007. High prevalence of antimicrobialresistant genes and integrons in Escherichia coli isolates from blackheaded gulls in the Czech Republic. J. Appl. Microbiol. 103:11-19.

Epstein J.H., Mckee J., Shaw P., Hicks V., Micalizzi G., Daszak P., Kilpatrick M. \& Kaufman G. 2007. The Australian white ibis (Threskiornis molucca) as a reservoir of zoonotic and livestock pathogens. EcoHealthy 3:290-298.

Evêncio J.N. 2006. Galliformes (mutum, jacu, jacutinga, aracuã, uru), p.169-184. In: Cubas Z.S., Silva J.C.R. \& Dias J.L.C. (Eds), Tratado de Animais Selvagens: medicina veterinária. Roca, São Paulo.

Ganapathy K., Saleha A.A., Jaganathan M., Tan C.G., Chong C.T., Tang S.C., Ideris A., Dare C.M. \& Bradbury J.M. 2007. Survey of Campylobacter, Salmonella and Mycoplasmas in house crows (Corvus splendens) in Malaysia. Vet. Rec. 160:622-624.

Gibbs P.S., Kasa R., Newbrey J.L., Petermann S.R., Wooley R.E., Vinson H.M. \& Reed W. 2007. Identification, antimicrobial resistance profiles, and virulence of members from the family Enterobacteriaceae from the feces of Yellow-Headed Blackbirds (Xanthocephalus xanthocephalus) in North Dakota. Avian Dis. 51:649-655.

Godoy-Vitorino F., Ley R.E., Gao Z., Pei Z., Ortiz-Zuazaga H., Perichi L.R., Garcia-Amado M.A., Michelangeli F., Blaser M.J., Gordon J.F. \& Domínguez-Bello M.G. 2008. Bacterial community in the crop of the hoatzin, a Neotropical folivorous flying bird. Appl. Environ. Microbiol. 74: 5905-5912.

Kapperud G. \& Rosef O. 1983. Avian wildlife reservoir of Campylobacter fetus subsp jejuni, Yersinia spp and Salmonella spp in Norway. Appl. Environ. Microbiol. 45: 75-380.

Koneman E.W. 2001. Diagnóstico Microbiológico: texto e atlas colorido. $5^{\mathrm{a}}$ ed. Guanabara Koogan, Rio de Janeiro. 1465p.

Koshland Jr D.E. 1994. The biological warfare of the future. Science 264:327.

Livermore D.M., Warner M., Hall L.M., Enne V.I., Projan S.J., Dunman P.M., Wooster S.L. \& Harrison G. 2001. Antibiotic resistance in bacteria from magpies (Pica pica) and rabbits (Oryctolagus cuniculus) from West Wales. Environ. Microbiol. 3:658-661.

Mattes B.R., Consiglio S.A.S., Almeida B.Z., Guido M.C., Orsi R.B., Silva R.M., Costa A., Ferreira A.J.P. \& Knobl T. 2005. Influência da biossegurança na colonização intestinal por Escherichia coli em psitacídeos. Arqs Inst. Biológico, São Paulo, 72:13-16.

Middleton J.H. \& Ambrose A. 2005. Enumeration and antibiotic resistance patterns of fecal indicator organisms isolated from migratory Canada Geese (Branta canadensis). J. Wildl. Dis. 41:334-341.

Nascimento A.M.A., Cursino L., Gonçalves-Dornelas H., Reis A., Chartone-Souza E. \& Marini M.A. 2003. Antibiotic-resistant gram-negative bacteria in birds from the Brazilian Atlantic Forest. The Condor 105:358-361.

National Comittee for Clinical Laboratory Standards, Performance Standards for Antimicrobials 2002. Performance standards for antimicrobial disk and dilution susceptibility tests for bacteria isolated from animals. Approved Standard M31-A2. Vol.22, no 6. NCCLS, Wayne, PA.

Quinn P.J., Carter M.E., Markey B. \& Carter G.R. 1994. Clinical Veterinary Microbiology. Wolf, London. 684p.

Refsum T., Heir E., Kapperud G., Vardund T. \& Holstad G. 2002. 
Molecular epidemiology of Salmonella enterica serovar Typhimurium isolates determined by pulsed-field gel electrophoresis: comparison of isolates from avian wildlife, domestic animals, and the environment in Norway. Appl. Environ. Microbiol. 68:5600-5606.

Sayah R.S., Kaneene J.B., Johnson Y. \& Miller R. 2005. Patterns of antimicrobial resistance observed in Escherichia coli isolates obtained from domestic- and wild-animal fecal samples, human septage, and surface water. Appl. Environ. Microbiol. 71:1394-1404.
Sedaghatkish G. 1996. The importance of seed dispersers in the conservation of useful wild plant species: A case study of the avian family Cracidae. MSc. Dissertation. College Park, University of Maryland, USA. 122p.

Steele C.M., Brown R.N. \& Botzler R.G. 2005. Prevalence of zoonotic bacteria among seabirds in rehabilitation centers along the Pacific Coast of California and Washington, USA. J. Wildl. Dis. 41:735-744. 